\title{
Anticariogenic potential of white cheese, xylitol chewing gum, and black tea
}

\author{
Pinar Gul ${ }^{1}$, Nilgun Akgul ${ }^{1}$, Nilgun Seven ${ }^{1}$
}

Correspondence: Dr. Pinar Gul

Email: opinargul@gmail.com 'Department of Restorative Dentistry, Faculty of
Dentistry, Atatürk University, Erzurum, Turkye

\section{ABSTRACT}

Objective: This study aimed to examine the effects of these foods on plaque $\mathrm{pH}$ and the potential development of tooth decay. Materials and Methods: Plaque $\mathrm{pH}$ was measured using the sampling method before and after 1, 5, 10, 20, 30, 45, and 60 min following consumption of these foods individually and after rinsing with a $10 \%$ sucrose solution. Statistical analysis was performed using one-way ANOVA and Tukey honestly significant difference post hoc tests $(\alpha=0.05)$. Results: Although there were statistically significant differences in all test groups except the BT $(P=0.620)$ and sucrose $+\mathrm{XCG}(P=0.550)$ groups in time, none of the participants chosen for this study were having a plaque $\mathrm{pH}$ value anywhere close to the critical value $(\mathrm{pH}=5.5)$. Conclusion: WC, BT, and XCG are advisable as anticariogenic foods because $\mathrm{pH}$ values are not below critical value.

Keywords: Black tea, dental health, plaque $\mathrm{pH}$, white cheese, xylitol chewing gum

\section{INTRODUCTION}

Dental caries are one of the diseases exposed by individuals. One contributing factor is carbohydrates in the diet. Sucrose and glucose in the mouth are fermented by microorganisms, mainly Streptococcus mutans, yielding lactic and other organic acids that cause erosion and decalcification, thus leading to the creation of cavities, decay, and the development of caries. ${ }^{[1,2]}$

Among the types of food mentioned in the literature as having anticariogenic components are black tea (BT), xylitol chewing gum (XCG), and white cheese (WC), all of which are commonly consumed during or after meals by members of the Turkish community. ${ }^{[3-9]}$ The fact that cheese has a ancariogenic effect may stem from several mechanisms.

Previously, cheese is one of the foods which stimulates the salivary flow. The second mechanism

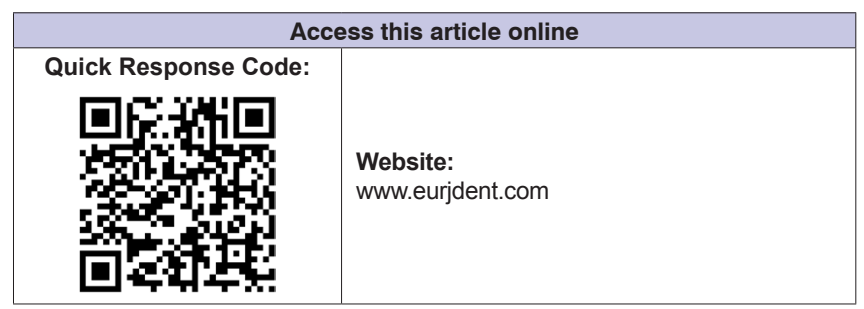

is that there is a strong relationship between the calcium and phosphate ions included in dental plaque. As a result of consumption of cheese, it enhances the concentration of calcium in plaque, which raises plaque $\mathrm{pH}$ above the critical level before demineralization occurs. Third, cheese contains casein, an anticariogenic phosphoprotein. Caries development decreases due to the casein in cheese. Casein from milk and cheese in saliva binds with hydroxyapatite to prevent the adhesion of $S$. mutans. ${ }^{[10-12]}$ It has been reported that casein phosphopeptides stabilize calcium phosphate by the formation of casein phosphopeptide-calcium phosphate complexes, thereby facilitating plaque calcium and phosphate uptake. Many studies have shown casein phosphopeptides to be anticariogenic. ${ }^{[10,11,13,14]}$

This is an open access journal, and articles are distributed under the terms of the Creative Commons Attribution-NonCommercial-ShareAlike 4.0 License, which allows others to remix, tweak, and build upon the work non-commercially, as long as appropriate credit is given and the new creations are licensed under the identical terms.

For reprints contact: reprints@medknow.com

How to cite this article: Gul P, Akgul N, Seven N. Anticariogenic potential of white cheese, xylitol chewing gum, and black tea. Eur J Dent 2018;12:199-203.

DOI: 10.4103/ejd.ejd_4_18 
Xylitol has been reported to directly decrease the growth of $S$. mutans and may prevent caries by limiting plaque formation and bacterial adherence. ${ }^{[15,16]}$ Xylitol's ability to inhibit the accumulation of plaque and $S$. mutans appears to be affected by xylitol content and frequency of usage. Xylitol cannot be fermented by most oral microorganisms. ${ }^{[2,3]}$

Tea contains fluoride, polyphenols, catechins (epicatechin, epicatechin gallate [ECG], and epigallocatechin gallate [EGCG]), and flavonoids. ${ }^{[11]}$ Tea, or some of its various components, has a direct bactericidal effect on $S$. mutans and prevents bacterial adherence to teeth. ${ }^{[17,18]}$ Polyphenols, which are abundant in BT, were determined to suppress the growth of $S$. mutans, reducing its ability to synthesize glucan and suppressing amylase activity. ${ }^{[11,17,19]}$ It was also reported that polyphenol compounds in BT caused to enhance the fluoride amount in plaque. ${ }^{[11]}$ Other studies have shown that catechins remain in saliva until $60 \mathrm{~min}$ following rinse of the mouth with tea. ${ }^{[17,20]}$

The purpose of this study was to examine the effects of $\mathrm{WC}$, tea, and xylitol on plaque $\mathrm{pH}$ and potential for tooth decay.

\section{SUBJECTS AND METHODS}

The study participants comprised of student volunteers from the Faculty of Dentistry selected in line with the recommendations of Wang et al. ${ }^{[2]}$ and Sönmez and Aras. ${ }^{[21]}$ The study was approved by the Ethical Committee of University, and all participants gave their informed consent.

All 10 participants (20-25 years old) were healthy, nonsmoking, and adults free of any periodontal disease. Salivary S. mutans and Lactobacillus levels of the participants were measured using Caries Risk Test Bacteria (Ivoclar Vivadent AG), and the buffering capacity of the participants was determined using Caries Risk Test Buffer (Ivoclar Vivadent AG). All the participants had salivary S. mutans and Lactobacillus levels below $10^{5}$ colony-forming unit/ $\mathrm{ml}$ and normal buffering capacity and unstimulated salivary flow rates $(0.3-0.4 \mathrm{ml} / \mathrm{min})$, suggesting them to be at low risk for caries development.

To facilitate adequate plaque accumulation, the participants were demanded to not brush their teeth $48 \mathrm{~h}$ prior to their test sessions. Participants were also demanded to stop eating or drinking anything for at least $2 \mathrm{~h}$ before testing. Applications of the all the test groups were started at 9:30 a.m.
Plaque $\mathrm{pH}$ was determined by the sampling method. ${ }^{[22]}$ On each test session, a sample of approximately $1 \mathrm{mg}$ of plaque was obtained from the buccal surfaces of the participant's first permanent molars using a sterile excavator, mixed with $50 \mu \mathrm{L}$ of distilled water, and the resting $\mathrm{pH}$ was measured ex vivo using a microelectrode (Perphect ${ }^{\mathrm{TM}}$ Ross $^{\mathrm{TM}}$ 8220BN, Thermo Scientific, USA) which had been previously calibrated with $\mathrm{pH} 7$ and $\mathrm{pH} 4$ buffer solutions.

Plaque $\mathrm{pH}$ was determined at baseline and after 1, 5, $10,20,30,45$, and $60 \mathrm{~min}$ the following treatments:

1. $10 \%$ sucrose solution $(10 \mathrm{ml})$ (control) (rinsed for $1 \mathrm{~min})$

2. $\mathrm{WC}(10 \mathrm{~g})$ (chewed for $1 \mathrm{~min}$ )

3. XCG (Vivident Xylit; Gum weight: 1.15 g; Xylitol content: $15.36 \%, 0.17 \mathrm{~g}$ ) (chewed for $1 \mathrm{~min}$ )

4. Tea solution $(10 \mathrm{ml})$ (Doğuş Çay) (solutions were prepared using $10 \mathrm{~g}$ [5 bags] of BT and $1 \mathrm{~L}$ double-distilled deionized water.) ${ }^{[23,24]}$ (rinsed for $1 \mathrm{~min}$ )

5. Sucrose $+\mathrm{WC}$ (WC chewed for 1 min 5 min after rinse with sucrose solution for $1 \mathrm{~min}$ )

6. Sucrose + chewing gum (chewing gum chewed for 1 min 5 min after rinse with sucrose solution for $1 \mathrm{~min})$

7. Sucrose + tea (tea rinsed for $1 \mathrm{~min} 5 \mathrm{~min}$ after rinse with sucrose solution for $1 \mathrm{~min}$ ).

Salivary contamination of plaque sample was avoided by asking participants to swallow just before plaque collection as well as blood contamination was also avoided during sample collection. Plaque was collected from the gingival margin of each of the four teeth sampled at each time interval, and the plaque samples were collected in $30 \mathrm{~s}$ for standardization.

\section{Statistical analysis}

The data were analyzed using SPSS version 18.0 (SPSS Inc., Chicago, IL, USA) software. $\mathrm{pH}$ values measured in time for each test group were analyzed using one-way ANOVA and Tukey honestly significant difference (HSD) post hoc tests $(\alpha=0.05)$.

\section{RESULTS}

Table 1 presents comparison of mean \pm standard deviation of $\mathrm{pH}$ values at different time intervals for test groups. One-way ANOVA and Tukey HSD tests indicated that there were statistically significant differences in all test groups except the BT $(P=0.620)$ and sucrose + XCG $(P=0.550)$ groups in time.

European Journal of Dentistry, Volume 12 / Issue 2 / April-June 2018 
Gul, et al.: Anticariogenic potential of some foods

\begin{tabular}{|c|c|c|c|c|c|c|c|c|c|}
\hline \multirow[t]{2}{*}{ Test groups } & \multicolumn{8}{|c|}{ Time periods } & \multirow[t]{2}{*}{$P$} \\
\hline & Baseline & $1 \mathrm{~min}$ & $5 \mathrm{~min}$ & $10 \mathrm{~min}$ & $20 \mathrm{~min}$ & $30 \mathrm{~min}$ & $45 \mathrm{~min}$ & $60 \mathrm{~min}$ & \\
\hline Sucrose & $7.57 \pm 0.19^{c}$ & $7.29 \pm 0.04^{a, b}$ & $7.23 \pm 0.23^{a}$ & $7.39 \pm 0.01^{a, b, c}$ & $7.44 \pm 0.09^{b, c}$ & $7.51 \pm 0.17^{c}$ & $7.49 \pm 0.22^{c}$ & $7.47 \pm 0.19^{b, c}$ & $0.001^{*}$ \\
\hline WC & $7.08 \pm 0.02^{\mathrm{a}}$ & $7.19 \pm 0.26^{a, b}$ & $7.29 \pm 0.22^{b}$ & $7.29 \pm 0.17^{b}$ & $7.26 \pm 0.11^{a, b}$ & $7.26 \pm 0.10^{a, b}$ & $7.26 \pm 0.05^{b}$ & $7.25 \pm 0.16^{a, b}$ & $0.009^{*}$ \\
\hline XCG & $6.89 \pm 0.11^{a}$ & $7.36 \pm 0.05^{d}$ & $7.24 \pm 0.09^{c}$ & $7.18 \pm 0.05^{b, c}$ & $7.10 \pm 0.08^{b}$ & $7.12 \pm 0.08^{b}$ & $7.17 \pm 0.06^{b, c}$ & $7.17 \pm 0.07^{b, c}$ & $0.001^{*}$ \\
\hline BT & $6.67 \pm 0.40^{\mathrm{a}}$ & $6.63 \pm 0.23^{a}$ & $6.71 \pm 0.29^{a}$ & $6.78 \pm 0.27^{a}$ & $6.75 \pm 0.15^{a}$ & $6.76 \pm 0.12^{\mathrm{a}}$ & $6.80 \pm 0.17^{a}$ & $6.72 \pm 0.19^{a}$ & 0.620 \\
\hline Sucrose + WC & $6.83 \pm 0.37^{b}$ & $6.75 \pm 0.04^{a, b}$ & $6.79 \pm 0.16^{b}$ & $6.57 \pm 0.16^{\mathrm{a}}$ & $6.88 \pm 0.01^{b}$ & $6.88 \pm 0.01^{\mathrm{b}}$ & $6.92 \pm 0.05^{b}$ & $6.82 \pm 0.01^{b}$ & $0.001^{*}$ \\
\hline Sucrose + XCG & $7.04 \pm 0.02^{\mathrm{a}}$ & $7.08 \pm 0.07^{a}$ & $6.98 \pm 0.23^{a}$ & $6.97 \pm 0.26^{\mathrm{a}}$ & $6.93 \pm 0.26^{a}$ & $6.97 \pm 0.25^{a}$ & $6.95 \pm 0.24^{a}$ & $7.01 \pm 0.06^{a}$ & 0.550 \\
\hline Sucrose + BT & $7.32 \pm 0.02^{\mathrm{d}}$ & $6.97 \pm 0.09^{a}$ & $7.12 \pm 0.02^{b}$ & $7.19 \pm 0.02^{c}$ & $7.22 \pm 0.07^{c}$ & $7.39 \pm 0.02^{\mathrm{e}}$ & $7.29 \pm 0.06^{d}$ & $7.20 \pm 0.09^{c}$ & $0.001^{*}$ \\
\hline
\end{tabular}

Plaque $\mathrm{pH}$ values were partially decreased after sucrose was consumed alone and with test groups. However, after ingestion of test groups other than sucrose, plaque $\mathrm{pH}$ values were higher than initial $\mathrm{pH}$ even after $60 \mathrm{~min}$. Although the $\mathrm{pH}$ values decreased following sucrose uptake, they generally increased above the baseline $\mathrm{pH}$ within $20 \mathrm{~min}$ after the test groups were taken. Although there were statistically significant differences, none of the participants chosen for this study were having a plaque $\mathrm{pH}$ value anywhere close to the critical value $(\mathrm{pH}=5.5)$.

\section{DISCUSSION}

Dental caries occurs as a result of three different stage: (1) bacterial adherence to the tooth; (2) glucan synthesis as a result of bacterial enzymes acting on sucrose; and (3) accumulation of biofilm (plaque) and ongoing acid production by bacteria. ${ }^{[17]}$

Evaluating the magnitude of the $\mathrm{pH}$ response after ingestion is one of the methods used to determine cariogenic potential of foods. Plaque $\mathrm{pH}$ measurements can be carried out using various methodologies, such as plaque sampling, touching plaque with electrodes, and implanting electrodes in the dentition for telemetric monitoring. ${ }^{[21,23,24]}$ However, the sampling method was chosen in the present study because this method is cheap and easy to apply.

In this study, it was found that there were statistically significant differences among plaque $\mathrm{pH}$ values for all the test groups except the BT $(P=0.620)$ and sucrose + XCG $(P=0.550)$ groups. Although there were statistically significant differences in all test groups, $\mathrm{pH}$ values were not below critical value $(\mathrm{pH}=5.5)$ in all the test groups. The results of this study are in accordance with other studies. ${ }^{[21,24]}$ Abelson and Mandel ${ }^{[25]}$ found differences in plaque $\mathrm{pH}$ responses to a sucrose mouthrinse between groups of caries-resistant and caries-susceptible individuals when salivary access was permitted; however, when saliva was excluded from plaque, no differences were found.

Previous studies have demonstrated the anticariogenic properties of WC, BT, and XCG; ; $[2,7,21]$ however, a literature search found no single study that addressed all the three items. Our study also suggests that WC, BT, and XCG may prevent the development of dental caries by maintaining plaque $\mathrm{pH}$ levels above 5.5 .

Moynihan et al. ${ }^{[26]}$ found significantly higher plaque $\mathrm{Ca}$ concentrations in individuals who ate meals containing cheese in comparison to controls who ate meals without cheese. Another study by Sönmez and $\operatorname{Aras}^{[21]}$ that examined the anticariogenic effects of WC and sugarless yogurt found that after these foods were consumed, plaque $\mathrm{pH}$ levels dropped below the critical $\mathrm{pH} 5.5$ at which demineralization occurs. A study by Silva et al. ${ }^{[27]}$ examined the effects of the water-soluble components of cheddar cheese on plaque $\mathrm{pH}$ by placing to five participants two bovine enamel, with one side of each appliance (experimental) dipped in a $25 \%$ water extract of the cheese and the other side (control) dipped in deionized water. The authors reported that the calcium and phosphorous concentrations in plaque did not show statistically significant difference between experimental and control groups. Another study on rats with surgically removed submandibular/sublingual glands and parotid ducts found that rats consumed a highly cariogenic diet and cheese significantly had fewer and less severe caries lesions on coronal and root surfaces than rats fed a noncariogenic diet only. ${ }^{[13]}$

Studies had indicated that cheese consumption in humans did not bring about decrease in plaque $\mathrm{pH} \cdot{ }^{[23,28]}$ Similarly, Rugg-Gunn et al. ${ }^{[29]}$ stated that consuming cheddar cheese after digestion of a sugary food quickly returned the plaque $\mathrm{pH}$ toward neutrality. They also stated that the stimulation of saliva flow was caused by the $\mathrm{pH}$-raising effect of cheese. As a result, authors 
stated that cheese may benefit in the reduction of caries due to its effect on plaque $\mathrm{pH}$. In accordance with this study, our study found that plaque $\mathrm{pH}$ was significantly increased by the consumption of cheese alone or following sucrose uptake.

Various studies have mentioned the anticariogenic properties of BT. In one study, both black and green teas were found to contain anticariogenic catechins, and in spite of their oxidation and condensation to larger, dark-colored molecules that included theaflavins and thearubigins during fermentation, some simple catechins continued to be present in BT. ${ }^{[17]}$ Tsuchiya et al. ${ }^{[20]}$ showed that catechins remained in saliva until 60 min after rinsing the mouth with tea. Zhang and Kashket ${ }^{[19]}$ found that both black and green teas inhibited amylase activity from $S$. mutans through the action of polyphenols, which are more abundant in BT than in green tea.

Studies have been conducted on polyphenol fractions of tea due to their antimicrobial properties. Previous studies have found that catechins from BT, especially ECG and EGCG, inhibited the growth of many bacterial species..$^{[5,30,31]}$ Lee et al..$^{[7]}$ found that catechins and theaflavins could be determined in saliva in the $1^{\text {st }} \mathrm{h}$ following the consumption of green tea and BT. They suggested tea leaves to be able to be used as the prevention of dental caries. In addition, Linke and LeGeros $^{[32]}$ found that frequent consumption of BT can significantly decrease caries development. In another study ${ }^{[33]}$ in which hamsters were fed a cariogenic diet containing sucrose with either water or tea, the group given tea developed fewer dental caries than those given water. The authors of this study suggested that the anticariogenic effects shown by tea were due to the action of both polyphenols and fluoride. Similarly, our study found that the BT increased the plaque $\mathrm{pH}$ above neutral $\mathrm{pH}$ in $5 \mathrm{~min}$ following sucrose consumption.

Studies in the literature also mention the anticariogenic effects of xylitol. Studies had shown that cariogenic microorganisms do not metabolize xylitol, and consuming xylitol does not decrease plaque $\mathrm{pH}$. Consequently, convenient use of xylitol-sweetened gum decreases salivary $S$. mutans counts. ${ }^{[34]}$ Wang et al. ${ }^{[2]}$ found that individuals given xylitol had lower levels of plaque accumulation and S. mutans than a control group. Ertuğrul et al. ${ }^{[1]}$ found that rats fed with a diet included in sucrose had significantly higher levels of $S$. mutans than those fed with xylitol. The authors attributed these results to the inability of S. mutans to ferment xylitol. A study by Haresaku et al. ${ }^{[35]}$ found that $S$. mutans' level in saliva and plaque declined significantly in individuals who chewed xylitol gum for 6 months, whereas plaque increased significantly in a control group given maltitol as a substitute for xylitol. There are parallel studies ${ }^{[36-38]}$ which examine the reduction of $S$. mutans as a result of use of xylitol. It has been universally agreed that xylitol helps to prevent the dental caries not only by increasing the $\mathrm{pH}$ of saliva and dental plaque, but also by decreasing the number of salivary microorganisms in the oral cavity. ${ }^{[39]}$ Similar to these findings, our study was found to increase the plaque $\mathrm{pH}$.

In the literature, although there are differences among studies with regard to time, the effects on plaque $\mathrm{pH}$ are similar. The differences observed may be due to the selection of participants with good oral hygiene and high saliva-buffering capacities.

\section{CONCLUSION}

WC, BT, and XCG are advisable as anticariogenic foods because none of the participants chosen for this study were having a plaque $\mathrm{pH}$ value anywhere close to the critical value $(\mathrm{pH}=5.5)$. However, caries is a multifactorial disease and the only measurement of $\mathrm{pH}$ value is not indicative of whether the caries will be generated. Therefore, it is suggested to do further comprehensive studies.

\section{Financial support and sponsorship}

This work was supported by the Research Fund of Ataturk University (Project number: 2008/205).

\section{Conflicts of interest}

There are no conflicts of interest.

\section{REFERENCES}

1. Ertuğrul F, Eltem R, Ataman B. Bacteriological effects of xylitol and different carbohydrate containing diets in swiss albino rats inoculated with Streptococcus mutans CCUG 6519. Turk J Med Sci 2002;32:13-9.

2. Wang YB, Chuang CY, Liao JF. Effects of xylitol in chewing gum on dental plaque and Streptococcus mutans. J Food Drug Anal 2006;14:84-8.

3. Giertsen E, Emberland H, Scheie AA. Effects of mouth rinses with xylitol and fluoride on dental plaque and saliva. Caries Res 1999;33:23-31.

4. Guggenheim B, Schmid R, Aeschlimann JM, Berrocal R, Neeser JR. Powdered milk micellar casein prevents oral colonization by Streptococcus sobrinus and dental caries in rats: A basis for the caries-protective effect of dairy products. Caries Res 1999;33:446-54.

5. Hamilton-Miller JM. Antimicrobial properties of tea (Camellia sinensis L.). Antimicrob Agents Chemother 1995;39:2375-7.

6. Lif Holgerson P, Stecksén-Blicks C, Sjöström I, Oberg M, Twetman S. Xylitol concentration in saliva and dental plaque after use of various xylitol-containing products. Caries Res 2006;40:393-7.

7. Lee MJ, Lambert JD, Prabhu S, Meng X, Lu H, Maliakal P, et al. Delivery 


\section{Gul, et al.: Anticariogenic potential of some foods}

of tea polyphenols to the oral cavity by green tea leaves and black tea extract. Cancer Epidemiol Biomarkers Prev 2004;13:132-7.

8. Rosen S, Min DB, Harper DS, Harper WJ, Beck EX, Beck FM, et al. Effect of cheese, with and without sucrose, on dental caries and recovery of Streptococcus mutans in rats. J Dent Res 1984;63:894-6.

9. Söderling E, Isokangas P, Pienihäkkinen K, Tenovuo J, Alanen P. Influence of maternal xylitol consumption on mother-child transmission of mutans streptococci: 6-year follow-up. Caries Res 2001;35:173-7.

10. Johansson I. Milk and dairy products: Possible effects on dental health. Scand J Nut 2002;46:119-22.

11. Moynihan PJ. Foods and factors that protect against dental caries. Nutr Bull 2000;25:281-6.

12. Vacca Smith AM, Bowen WH. The effects of milk and kappa-casein on salivary pellicle formed on hydroxyapatite discs in situ. Caries Res 2000;34:88-93.

13. Krobicka A, Bowen WH, Pearson S, Young DA. The effects of cheese snacks on caries in desalivated rats. J Dent Res 1987;66:1116-9.

14. Reynolds EC, Cain CJ, Webber FL, Black CL, Riley PF, Johnson IH, et al. Anticariogenicity of calcium phosphate complexes of tryptic casein phosphopeptides in the rat. J Dent Res 1995;74:1272-9.

15. American Academy on Pediatric Dentistry Council on Clinical Affairs. Policy on the use of xylitol in caries prevention. Pediatr Dent 2008;30:36-7.

16. Trahan L, Mouton C. Selection for Streptococcus mutans with an altered xylitol transport capacity in chronic xylitol consumers. J Dent Res 1987;66:982-8.

17. Hamilton-Miller JM. Anti-cariogenic properties of tea (Camellia sinensis). J Med Microbiol 2001;50:299-302.

18. Matsumoto M, Minami T, Sasaki H, Sobue S, Hamada S, Ooshima T, et al. Inhibitory effects of oolong tea extract on caries-inducing properties of mutans streptococci. Caries Res 1999;33:441-5.

19. Zhang J, Kashket S. Inhibition of salivary amylase by black and green teas and their effects on the intraoral hydrolysis of starch. Caries Res 1998;32:233-8.

20. Tsuchiya H, Sato M, Kato H, Okubo T, Juneja LR, Kim M, et al. Simultaneous determination of catechins in human saliva by high-performance liquid chromatography. J Chromatogr B Biomed Sci Appl 1997;703:253-8.

21. Sönmez IS, Aras S. Effect of white cheese and sugarless yoghurt on dental plaque acidogenicity. Caries Res 2007;41:208-11.

22. Saeed S, Bshara N, Trak J, Mahmoud G. Effect of dietary combinations on plaque $\mathrm{pH}$ recovery after the intake of pediatric liquid analgesics. Eur J Dent 2015;9:340-5.

23. Jensen ME, Schachtele CF. The acidogenic potential of reference foods and snacks at interproximal sites in the human dentition.
J Dent Res 1983;62:889-92.

24. Simpson A, Shaw L, Smith AJ. Tooth surface $\mathrm{pH}$ during drinking of black tea. Br Dent J 2001;190:374-6.

25. Abelson DC, Mandel ID. The effect of saliva on plaque $\mathrm{pH}$ in vivo. J Dent Res 1981;60:1634-8.

26. Moynihan PJ, Ferrier S, Jenkins GN. The cariostatic potential of cheese: Cooked cheese-containing meals increase plaque calcium concentration. Br Dent J 1999;187:664-7.

27. Silva MF, Burgess RC, Sandham HJ, Jenkins GN. Effects of water-soluble components of cheese on experimental caries in humans. J Dent Res 1987;66:38-41.

28. Graf H. The glycolytic activity of plaque and its relation to hard tissue pathology: Recent findings from intraoral $\mathrm{pH}$ telemetry research. Int Dent J 1971;20:426-35.

29. Rugg-Gunn AJ, Edgar WM, Geddes DA, Jenkins GN. The effect of different meal patterns upon plaque $\mathrm{pH}$ in human subjects. Br Dent J 1975;139:351-6.

30. Ahn YJ, Kawamura T, Kim M, Yamamoto T, Mitsuoka T. Tea polyphenols-selective growth-inhibitors of Clostridium spp. Agric Biol Chem 1991;55:1425-6.

31. Otake S, Makimura M, Kuroki T, Nishihara Y, Hirasawa M. Anticaries effects of polyphenolic compounds from Japanese green tea. Caries Res 1991;25:438-43.

32. Linke HA, LeGeros RZ. Black tea extract and dental caries formation in hamsters. Int J Food Sci Nutr 2003;54:89-95.

33. Linke HA, Salgado T, Retino M, Legeros RZ. Effect of black tea on caries formation in hamsters. J Dent Res 2000;79:594.

34. Burt BA. The use of sorbitol- and xylitol-sweetened chewing gum in caries control. J Am Dent Assoc 2006;137:190-6.

35. Haresaku S, Hanioka T, Tsutsui A, Yamamoto M, Chou T, Gunjishima $\mathrm{Y}$, et al. Long-term effect of xylitol gum use on mutans streptococci in adults. Caries Res 2007;41:198-203.

36. Jannesson L, Renvert S, Kjellsdotter P, Gaffar A, Nabi N, Birkhed D, et al. Effect of a triclosan-containing toothpaste supplemented with $10 \%$ xylitol on mutans streptococci in saliva and dental plaque. A 6-month clinical study. Caries Res 2002;36:36-9.

37. Kakuta H, Iwami Y, Mayanagi H, Takahashi N. Xylitol inhibition of acid production and growth of mutans streptococci in the presence of various dietary sugars under strictly anaerobic conditions. Caries Res 2003;37:404-9.

38. Park K, Schemehorn BR, Bolton JW, Stookey GK. Effect of sucrose and sorbitol gums on plaque $\mathrm{pH}$ responses. J Dent Res 1991;70:404.

39. Kumar S, Sogi SH, Indushekar KR. Comparative evaluation of the effects of xylitol and sugar-free chewing gums on salivary and dental plaque $\mathrm{pH}$ in children. J Indian Soc Pedod Prev Dent 2013;31:240-4 